Research Journal of Applied Sciences, Engineering and Technology 5(21): 5042-5045, 2013

DOI:10.19026/rjaset.5.4394

ISSN: 2040-7459; e-ISSN: 2040-7467

(C) 2013 Maxwell Scientific Publication Corp.

Submitted: September 14, 2012

Accepted: November 05, 2012

Published: May 20, 2013

\title{
Research Article \\ Research on Emergency Material Distribution Method Decision-making Based on Reliability
}

\author{
Wang Min, Duan Zhijian, Li Gailing and Wang Wenzhao \\ Military Logistics Department, Academy of Military Transportation, Tianjin, China
}

\begin{abstract}
Timeliness and reliability are important standards for emergency material distribution decision-making. In this study, emergency material distribution system is analyzed, concept for reliability of emergency material distribution method is defined and calculation method of it is presented. On the basis of that, decision model of emergency material distribution method based on reliability is built up. This is a new method for emergency material distribution.
\end{abstract}

Keywords: Decision model, distribution method, emergency material, reliability

\section{INTRODUCTION}

Emergency material is a general name for resources responded to accidents. Emergency material distribution is a kind of logistics activity for meeting the material request of accidents, maximizing time utility and minimizing the lost of disaster. From 2003 to now, some disasters happened such as "SARS", "Avian Influenza", "South Snowstorm", "Wenchuan Earthquake" and so on. Lots of materials are required to bury the dead, rescue the wounded, epidemic prevention, post disaster reconstruction, production recovery etc. They highlight the importance of emergency material distribution.

Emergency material distribution is deeply studied by domestic and oversea scholars. Such as Kemball Cook and Stephenson, who present that enhance management of relief goods to promote the transportation efficiency (Kemball-cook and Stephenson, 1984). Linet set up decision support system of relief goods and relief goods distribution model of multi-stage and multi-target (Linet, 2004). Chen chunyi built up operation model for emergency material supply and delivery center (Chen et al., 2001). With the targets of minimize whole stockout and minimize transportation cost, Zheng (2009) made multi-target optimization model of emergency material distribution and present the solution algorithm of it, etc. (Zhang and Wang, 2012).

However, emergency material distribution is different from general logistics activity. Emergency material distribution usually is used for relief materials which concerns the life and whole situation. So emergency material distribution has high timeliness. At the same time, communication, electricity may be interrupted, transportation route may be paralyzed or traffic jam happened, which will cause the risk for emergency material distribution. Therefore, it is difficult for emergency material distribution decisionmaking to select emergency material distribution method and complete the mission of distribution in stipulated time. Therefore, it is important to study the reliability of emergency material distribution. Currently, there are fewer researches in this respect and it is still in its infancy. Based on that, the emergency material distribution system is analyzed in this study. Concept and calculation method of emergency distribution reliability are defined, then the emergency material distribution model on the basis of time reliability is built.

\section{EMERGENCY MATERIAL DISTRIBUTION METHOD AND ITS RELIABILITY}

Emergency material distribution system: Emergency material distribution system is a complicated system which includes the different function links of material assembly, loading and unloading, transportation and distribution etc. The key factors influence this system mainly include environment factors, hardware factors, software factors and comprehensive factors. Environment factor is the nature environment of distribution such as topography, geology, traffic ability and fire safety etc. Hardware factors of distribution include comprehensive traffic net condition of land, sea and air, vehicles and object of delivery etc. Software factors of distribution include process coordination, organizing and command etc. (Wang et al., 2010). Comprehensive factors of distribution mainly include transportation support, information support and material

Corresponding Author: Hao Qiang, Department of Science and Engineering, Changzhou University, Changzhou, Jiangsu, 213164, China

This work is licensed under a Creative Commons Attribution 4.0 International License (URL: http://creativecommons.org/licenses/by/4.0/). 


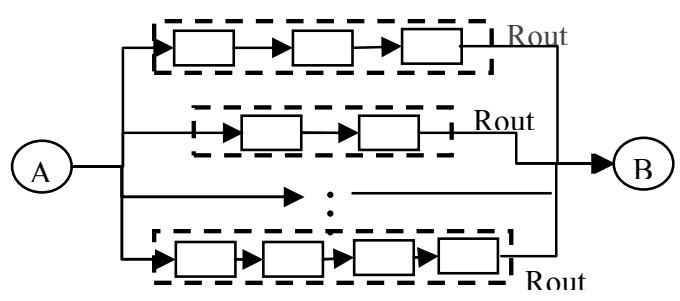

Fig. 1: Emergency material distribution system sketch

financing etc. For disasters happen in different locations, types, characters and sizes, the emergency material distribution systems will be not the same. Considering general characters during the emergency material distribution, emergency material distribution system from emergency material storage or emergency material marshalling area $\mathrm{A}$ to disaster area $\mathrm{B}$ can be shown by Fig. 1.

In Fig. 1 Solid line box means logistics unit, such as material loading, rail transport, air transport, unloading and delivery etc. These logistics units have independent input/output interface and can complete the given functions. Every dotted line box is combined by several solid line boxes, which means a delivery route from area A to area B. In emergency material distribution system, different distribution routes combined emergency material distribution method set. Emergency material distribution decision-making is to select an optimizing method satisfied reliability condition with lowest cost in the method set.

Reliability of emergency material distribution method: There are different explanations in different areas for concept of reliability (Bogers and Van Zuylen, 2004). Reliability of emergency material distribution is defined as the probability of materials transported from storage or staging area to disaster area through distribution method under stated conditions for a specified period of time. Emergency material distribution method is combined by several logistics functional units according to certain connection mode. Not only reliability of each logistics functional unit but also connection relationship of each logistics functional unit should be considered for calculating reliability of emergency material distribution method.

Calculation of emergency material distribution method usually has two structures such as serial relations and parallel relations with known the reliabilities of each logistics functional unit. The reliabilities of those two structures are analyzed below:

Serial relation: Suppose route 1 in Fig. 1 is selected as an emergency material distribution method, then $\mathrm{m}$ logistics functional units combine serial relation in this method. The output of former logistics functional unit is the input of the later logistics functional unit. System can operate normally only when all of logistics functional units work normally. Then reliability $R_{j}$ of emergency material distribution method $i$ can be calculated as follows:

$$
R_{i}=\prod_{j=1}^{m} R_{i j}(j=1,2, \cdots, m)
$$

where, $R_{i j}$ is logistics functional unit $\mathrm{j}$ of method $\mathrm{i}$.

Parallel relation: Suppose route 1 and route 2 in Fig. 1 are selected as an emergency material distribution method together, in fact, the distribution method is a parallel connection of several logistics functional units connected serially. Serial connection system should be considered as a logistics unit in order to calculate the reliability of this method. Route 1 and route 2 can be regarded as 2 logistics units. In fact, these 2 logistics units constitute parallel relation. Each logistics unit can perform task of material distribution and can replace each other. Therefore, reliability $R_{P}$ of parallel emergency material distribution method can be calculated as follows (Xiao-chuan and Jian-hua, 2007):

$$
R_{p}=\frac{\sum_{i=1}^{n} R_{p i} \cdot Q_{p i}}{Q_{0}}
$$

In which, $R_{p i}$ is reliability of logistics unit $\mathrm{i}$ in parallel structure and reliability of distribution route $i$, which can be calculated through Eq. (1). $Q_{p j}$ is logistics volume of logistics unit i parallel structure, $Q_{0}$ is total volume of emergency material distribution

\section{DECISION MODEL OF EMERGENCY MATERIAL DISTRIBUTION METHOD}

Reliabilities of each emergency material distribution method can be calculated through Eq. (1) and (2). Decision-making of emergency material distribution method is selecting a material distribution method with minimum logistics cost and can meet a certain reliability requirement after considering above reliabilities. Therefore, with a given reliability, cost is often an optimal target for decision makers during material distribution method decision.

Emergency material distribution method is combined by different routes, which are combined by different logistics units. The logistics cost of logistics unit is related to its logistics service quantity and reliability. Thus, suppose the cost of logistics unit $J$ in route $i$ is $C_{i j}$, logistics service quantity is $Q_{i}$ and reliability is $\mathrm{R}_{\mathrm{ij}}$. Then logistics cost function of logistics unit is $C_{i j}=C_{i j}\left(Q_{i}, R_{i j}\right)$. Suppose route $i$ in emergency material method is $\mathrm{k}_{\mathrm{i}} \cdot \mathrm{k}_{\mathrm{i}}=1$ means route $\mathrm{i}$ is included in this emergency material method. $\mathrm{k}_{\mathrm{i}}=0$ means route $i$ is not included in this emergency material method. So cost function of each emergency material method is: 


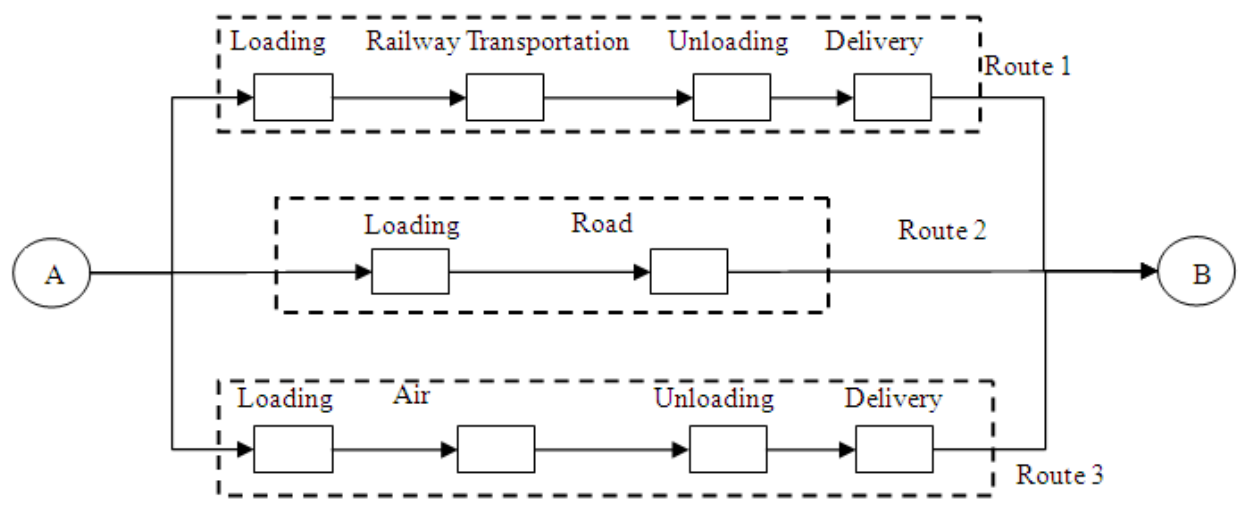

Fig. 2: Emergency material distribution system diagram

$$
\mathrm{C}=\sum_{i=1}^{n} \sum_{j=1}^{n_{i}} k_{i} C_{i j}\left(Q_{i}, R_{i j}\right)
$$

In which, $n_{i}$ is the number of active logistics unit for route $i$. Decision model of emergency material distribution method can be built up as follows:

$$
\begin{array}{ll}
\min C= & \sum_{i=1}^{n} \sum_{j=1}^{n_{i}} k_{i} C_{i j}\left(Q_{i}, R_{i j}\right) \\
& R=\frac{\sum_{i=1}^{n} k_{i} Q_{i} \prod_{j=1}^{n_{i}} R_{i j}}{Q_{0}} \geq R_{0} \\
\text { s.t. } \quad & \sum_{i=1}^{n} k_{i} Q_{i}=Q_{0} \\
& k_{i}=0 ; 1
\end{array}
$$

If the quantity of distribution route in emergency material distribution system is $n$, there are $2^{\mathrm{n}}-1$ of emergency material distribution methods in set. Enumeration method can be used to solve above function when the value of $\mathrm{n}$ is small. Computer program can be used when value of $n$ is large. Then optimal emergency material distribution method can be confirmed with meeting a certain reliability requirement.

\section{EXAMPLE}

Suppose there needs to make decision for an emergency material distribution method. Considering there are 3 routes from material assembly area A to disaster area B. Each distribution route is combined by different logistics units, shown in Fig. 2. Services of each logistics unit have typical scale effect, logistics cost and quantity of logistics service have the relationship of concave function. Reliability of logistics unit has the opposite impact on logistics cost. Increased reliability leads to a substantial increase in service cost of logistics unit. Therefore, suppose each logistics cost of unit, quantity of logistics service and reliability meet the relationship of function:

$$
C_{i j}=\alpha_{i j} \sqrt{Q_{i}}+\beta_{i j} R_{i j}^{2}
$$

where,

$\alpha_{i j}=$ Costs influence coefficient

$\beta_{i j}=$ Reliability influence coefficient

The referenced values of costs influence coefficient, reliability influence coefficient and reliability for each logistics unit in 3 routes are shown in Table 1. Bases on above data, we can confirm the optimized material distribution methods under condition that reliability is 0.9 , weight of material are 5 tons, 50 tons and 200 tons.

Because there are 3 routes in this emergency material distribution system, 7 kinds of emergency material distribution methods can be got when value of $k_{i}(\mathrm{I}=1,2,3)$ is 0 or 1 . Firstly, reliability of 3 routes can be calculated through Eq. (1), $\mathrm{R}_{1}=0.894, \mathrm{R}_{2}=$ $0.977, \mathrm{R}_{3}=0922$. Cost functions of 3 routes are $C_{1}=3.79 \sqrt{Q}+12.33, C_{2}=9.12 \sqrt{Q}+11.72 \mathrm{C} 3=108 \sqrt{Q}+$ 7.63 For the values of reliability for route 2 and 3 are both larger than 0.9 , the method combined by route 2 and route 3 will not be included in optimal distribution method, that is $\mathrm{k}_{2}$ and $\mathrm{k}_{2}$ cannot be 1 at same time. Thus, there are 5 methods in the set of optimal method being made up of $\mathrm{k}_{\mathrm{i}}(\mathrm{i}=1,2,3)$. That is $\mathrm{Mi}=\{\mathrm{k} 1, \mathrm{k} 2$, $\mathrm{k} 3\}=\{(1,0,0),(0,1,0),(0,0,1),(1,1,0),(1,0,1)\}$. The optimal costs with delivery weight of 5 tons, 50 tons and 200 tons can be calculated through Eq. (1) and (2). They are shown in Table 2.

From Table 2, it can be seen that the method of $(0$, $0,1)$ should be selected when delivery weight is 5 tons. That is select route 3 as independent delivery. The reliability is 0.922 and lowest cost of delivery is 318 
Res. J. Appl. Sci. Eng. Technol., 5(21): 5042-5045, 2013

Table 1: Influence coefficient $\left(\alpha_{\mathrm{ij}}, \beta_{\mathrm{ij}}, \mathrm{R}_{\mathrm{ij}}\right)$

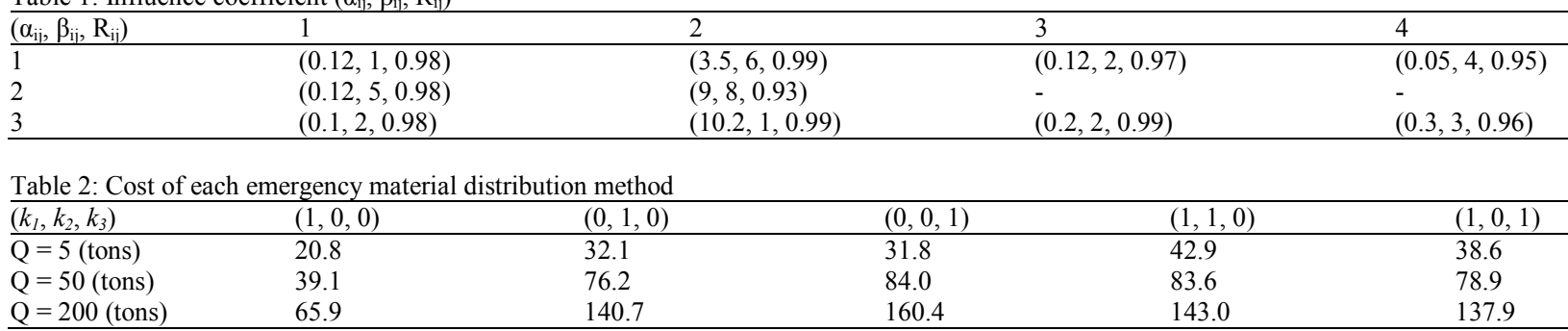

thousand Yuan. If delivery weight is 50 tons, method $(0,1,0)$ should be selected, that is select route 3 as independent delivery. The reliability is 0.911 and lowest cost of delivery is 762 thousand Yuan. If delivery weight is 200 tons, method $(1,0,1)$ should be selected, that is select route 1 and route 3 as combined delivery. In which 157.5 tons of material are delivered through route 1 and other 42.5 tons of material are delivered through route 3 . The reliability is 0.9 and lowest cost is 1.379 million Yuan.

\section{CONCLUSION}

Volume of material distribution, reliability of distribution and cost of distribution are key factors for influencing investment decision during decisionmaking of emergency materials distribution method. In this study, emergency material distribution system is analyzed. Calculation methods of different reliability of emergency material distribution method are presented. Decision model of emergency material distribution method that meeting a certain reliability requirement is built up. It has been proved to be scientific and operable through examples. Effective guidance is provided for decision-making of emergency material distribution.

\section{REFERENCES}

Bogers, E.A.I. and H.J. Van Zuylen, 2004. The /Importance of reliability in route choice in freight transport for various actors on various levels. Proceedings of the European Transport Conference, Strabourg, France, pp: 49-161.
Chen, C.Y., P.Y. Napoleon, C. Li-Yun, C. Yi, K. Yuang-kuang, et al., 2001. The Construction of Taiwan's Mitigating Logistics System. National Cheng Kung University, Taiwan.

Kemball-cook, D. and R. Stephenson, 1984. Lessonin logistics from Somalia. Dis-aster, 8: 57-66.

Linet, O.E., 2004. Emergency logistics planning in nature disasters. Ann. Operat. Res., 129: 217-245.

Wang, M., Y. Liu and H. Jiao, 2010. Study on evaluation of risk in emergency material reserve entrusted to other enterprises. International Conference on Internet Technology and Applications, Wuhan, pp: 1-4.

Xiao-chuan, Y. and J. Jian-hua, 2007. The researches on the optimization reliability of logistics system. J. Ind. Eng. Manage., 21(1): 67-70.

Zhang, X. S. and W. Wang, 2012. Study on optimum emergency material dispatching based on network reliability. Logis. Technol., 31: 235-238.

Zheng, Z.W., 2009. Building the emergency logistics supply chain based on the reliable technology. Acad. J. China Bus. Mark., 23: 10. 